\title{
Long-Lasting Effects of Oxy- and Sulfoanalogues of L-Arginine on Enzyme Actions
}

\author{
Tatyana A. Dzimbova, ${ }^{1}$ Peter B. Milanov, ${ }^{2,3}$ and Tamara I. Pajpanova ${ }^{1}$ \\ ${ }^{1}$ Institute of Molecular Biology, Bulgarian Academy of Sciences, 1113 Sofia, Bulgaria \\ ${ }^{2}$ Faculty of Mathematics and Natural Sciences, South-West University "Neofit Rilski", 2700 Blagoevgrad, Bulgaria \\ ${ }^{3}$ Institute of Mathematics and Informatics, Bulgarian Academy of Sciences, 1113 Sofia, Bulgaria \\ Correspondence should be addressed to Tatyana A. Dzimbova; tania_dzimbova@abv.bg
}

Received 5 June 2013; Revised 20 August 2013; Accepted 15 September 2013

Academic Editor: Hieronim Jakubowski

Copyright (C) 2013 Tatyana A. Dzimbova et al. This is an open access article distributed under the Creative Commons Attribution License, which permits unrestricted use, distribution, and reproduction in any medium, provided the original work is properly cited.

\begin{abstract}
Arginine residues are very important for the structure of proteins and their action. Arginine is essential for many natural processes because it has unique ionizable group under physiological conditions. Numerous mimetics of arginine were synthesized and their biological effects were evaluated, but the mechanisms of actions are still unknown. The aim of this study is to see if oxy-and sulfoanalogues of arginine can be recognized by human arginyl-tRNA synthetase (HArgS) - an enzyme responsible for coupling of $\mathrm{L}$-arginine with its cognate tRNA in a two-step catalytic reaction. We make use of modeling and docking studies of adenylate kinase (ADK) to reveal the effects produced by the incorporation of the arginine mimetics on the structure of ADK and its action. Three analogues of arginine, L-canavanine (Cav), L-norcanavanine (NCav), and L-sulfoarginine (sArg), can be recognized as substrates of HArgS when incorporated in different peptide and protein sequences instead of L-arginine. Mutation in the enzyme active center by arginine mimetics leads to conformational changes, which produce a decrease the rate of the enzyme catalyzed reaction and even a loss of enzymatic action. All these observations could explain the long-lasting nature of the effects of the arginine analogues.
\end{abstract}

\section{Introduction}

Peptidomimetics have found wide application as bioavailable, biostable, and potent mimetics of naturally occurring biologically active peptides. L-Arginine has guanidinium group, which is positively charged at neutral $\mathrm{pH}$ and is involved in many important physiological and pathophysiological processes [1]. It has a very ionizable amino acid, and it is found most frequently buried in the protein interior [2-5]. Arginine residues are essential in a variety of biological processes, such as the regulation of conformation or redox potentials $[6,7]$; viral capsid assembly [8]; electrostatic steering [9]; voltage sensing across lipid bilayers [10-12]; $\mathrm{H}+$ transport [6, 13$15]$ and peptide translocation across bilayers [16, 17]. They also play a critical role at protein-protein interfaces $[5,16]$, in enzymatic active sites $[3,5,18]$, and in variety of transport channels $[19,20]$. More recent findings show that argininespecific methylation of histones may cooperate with other types of posttransitional histone modification to regulate chromatin structure and gene transcription [21]. Proteins that methylate histones on arginine residues can collaborate with other coactivators such as nuclear receptors.

Enzymes are probably the most studied biological molecules. They constitute nature's toolkit for making and breaking down the molecules required by cells in the course of growth, repair, maintenance, and death. Virtually, every biological process requires an enzyme at some point. Enzymes are capable of carrying out complex transformations in aqueous solution, at biological temperatures and $\mathrm{pH}$, and in a stereospecific and regiospecific manner, a feat seldom achieved by the best of organic chemists [3, 22]. Crystallographic and NMR studies of enzymes have shed light on the relationship between an enzyme's three-dimensional (3D) structure and the chemical reaction it performs. There are many complications, however, in assigning the functions of catalytic residues, due to the multistep nature of a chemical reaction. One residue can play more than one role and can be involved in different steps of the reaction. 


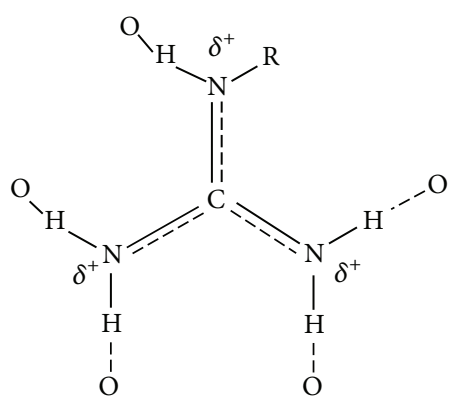

FIGURE 1: Schematic presentation of the hydrogen bond formation of the guanidinium group with 5 different oxygen atoms.

Arginine (Arg) is one of the most important residues in catalytic centers of many enzymes. Arg is in the 3rd place of the enzymatic frequency distribution and constitutes $11 \%$ of catalytic residues [3]. Arg occurs more frequently than other basic residues (e.g., lysine) because it has three nitrogen containing groups in the side chain, all of which can perform electrostatic interactions. The side chain of Arg can participate therefore in many electrostatic interactions, and it can be positioned more accurately to facilitate catalysis. The Arg side chain has also a favorable geometry to stabilize a pair of oxygen atoms on a phosphate group (Figure 1), a common biological moiety [3]. Arg in a catalytic center can be involved in various kinds of interactions, for example, electrostatic, hydrogen bond formation, transition state stabilization, activation of water, and the activation of substrates.

If the Arg residue in the active site of the enzymes is replaced by an Arg mimetic, this will cause the loss of enzymatic action, thus disturbing many metabolic pathways. This probably could be the reason for cell disorders. Adenylate kinase $(\mathrm{ADK})$ was chosen as an example in order to explore how Arg analogues will affect enzymatic action. This enzyme catalyzes the reversible reaction

$$
2 \mathrm{ADP} \leftrightarrows \mathrm{ATP}+\mathrm{AMP}
$$

and may process metabolic signals associated with ATP use [23-28]. In this case, ADK has been implicated in the regulation of the metabolically sensitive ion channels and transporters [29-32]. In addition, disruption of the ADK gene impedes the export of ATP from the mitochondria [33]. What will happen if a gene is working but some mutation of ADK appears, such as arginine analogues (Cav, NCav, NCan, NsArg, and sArg) being incorporated instead of Arg in the active site of the enzyme?

In order to study this issue, docking of analogues with arginyl-tRNA synthetase was our choice for the first step. This should show if analogues could be recognized by the enzyme responsible for transportation of arginine residues [34]. Aminoacyl-tRNA constitutes a family of RNA-binding proteins, that is, responsible for the correct translation of the genetic code by covalently linking the appropriate amino acid to the $3^{\prime}$ end of the correct tRNA. In most organisms, there are 20 distinct aminoacyl-tRNAs, with each one of them being responsible for aminoacylating its cognate tRNA with unique amino acid in a two-step catalytic reaction<smiles>N=C(N)NOCCC(N)C(=O)O</smiles><smiles>N=C(N)NOC(N)C(=O)O</smiles><smiles>NOC(N)C(=O)O</smiles><smiles>N=C(N)NS(=O)(=O)CCC(N)C(=O)O</smiles>

NCav

NCan

sArg<smiles>N=C(N)NS(=O)(=O)C(N)C(=O)O</smiles>

NsArg

FIGURE 2: Structures of the investigated arginine analogues.

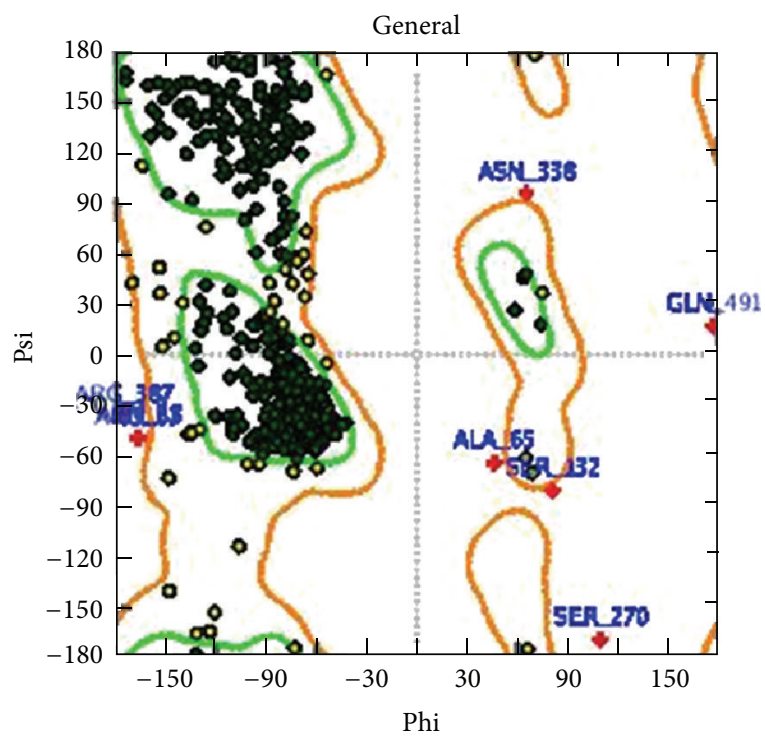

FIgURE 3: Ramachandran plot of HArgS, obtained from MOE: most favorable regions are $-80.8 \%$, allowed regions are $-18.3 \%$, and disallowed regions are $-0.9 \%$; outliers were presented with + .

[35]. The mechanism of their action is well known. The synthetase first binds ATP and corresponding amino acid to form acetylamino-AMP. This intermediate interacts with appropriate tRNA molecule, and amino acid is transferred to $3^{\prime}$ end of the tRNA.

\section{Methods}

2.1. Enzymes and Arginine Analogues. The protein sequence for human arginyl-tRNAsynthetase (HArgS) was obtained from the UniProt database (accession number Q5T160) [34]. Oxy- and sulfoarginine analogues: L-canavanine (Cav), L-norcanavanine (NCav), L-norcanaline (NCan), L-norsulfoarginine (NsArg) and L-sulfoarginine (sArg), were previously synthesized and biologically tested [36-39] (Figure 2).

2.2. Computational Tools. In order to perform computational studies, the following software was used in the present work: compound preparation and homology modeling were done 


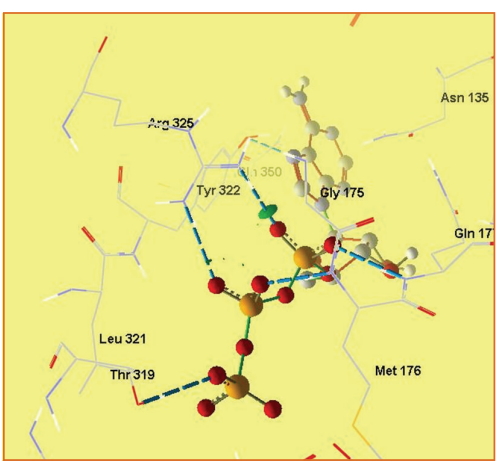

(a)

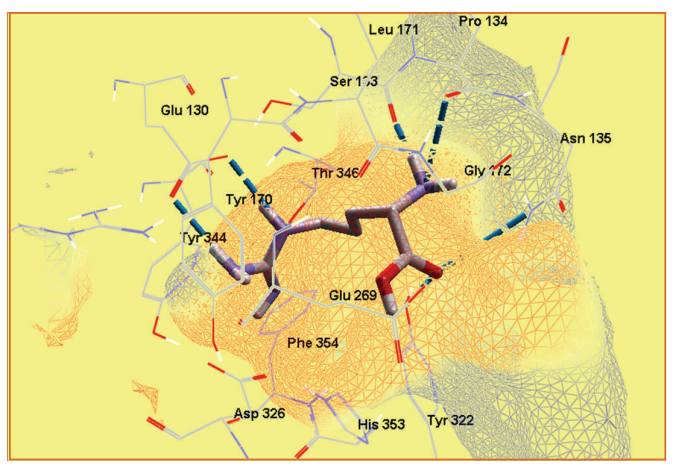

(b)

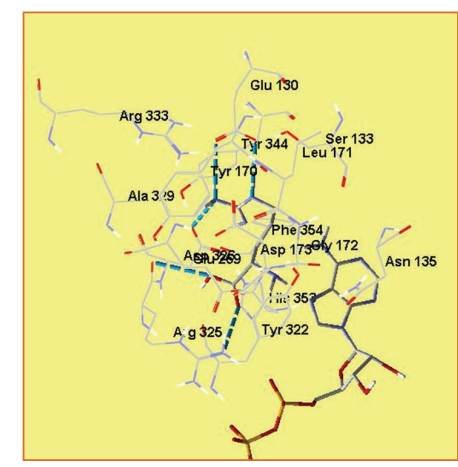

(c)

FIGURE 4: Binding of ATP to HArgS (a), L-arginine to HArgS without ATP (b), and L-arginine to HArgS with ATPc.

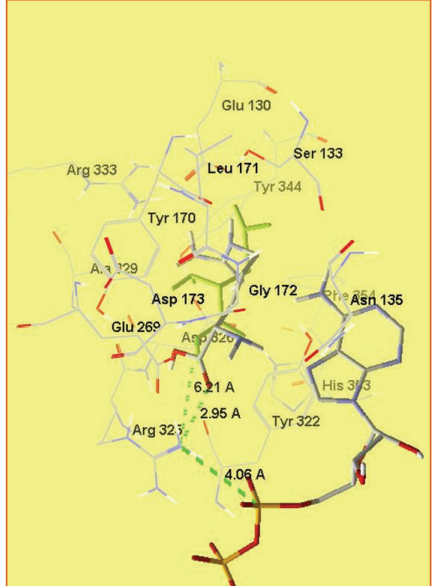

(a)

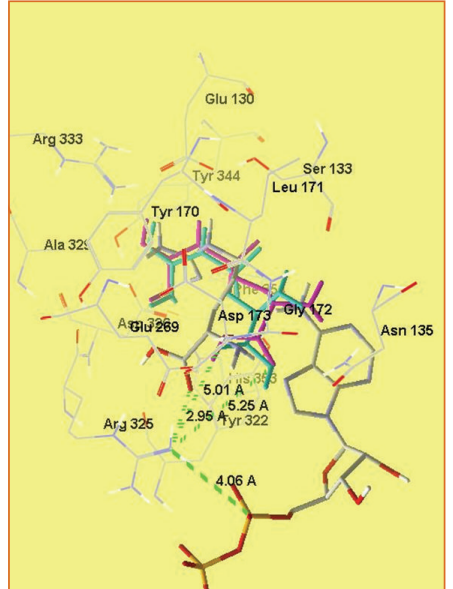

(b)

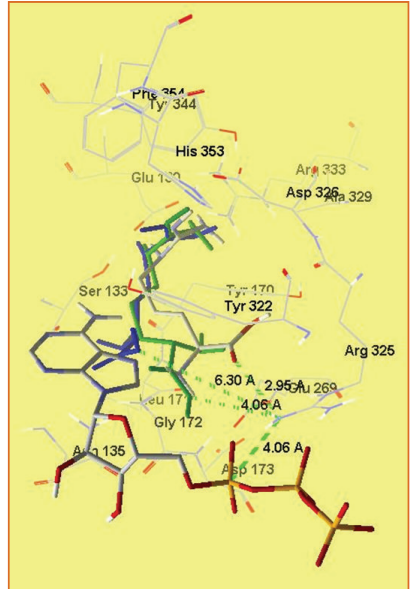

(c)

FIGURE 5: Arginine analogues superposed in the active site: arginine, dark green-Cav, light green-NCan, dark blue-NCav, light blue-NsArg, and purple-sArg.

with Molecular Operating Environment (MOE) [40]; docking studies were performed by using Genetic Optimization for Ligand Docking (GOLD 5.1) [41], run on the Scientific LINUX 5.5 operating system [42]; for generation of figures and the exploration of interactions after docking, the Molegro Molecular Viewer (MMV) [43, 44] was applied.

2.3. Homology Modeling. It was based on a single template and was performed with MOE. The best hit was proved with the crystallographic structure of arginyl-tRNA synthetase (ArgS) of Saccharomyces cerevisiae (Protein Data Bank [45]PDB Id: 1f7u) with $40 \%$ identity.

2.4. Docking of Arginine Analogues. Five oxy- and sulfoanalogues of arginine with already known in vivo and in vitro biological effects were selected for docking studies. 3D structures of the compounds were modeled with MOE and protonated at physiological pH. Docking was carried out with GOLD 5.1 software. It uses a genetic algorithm and considers full ligand conformational flexibility and partial protein flexibility. The active site of HArgS was defined as residues within $10 \AA$ radius of Glu130, which is responsible for guanidinium group recognition.

2.5. Mutations of Adenylate Kinase (ADK). One arginine residue seems to be very important at the active site of the enzyme-Arg138. Arg175 is very close to the active site, and it could play a role in catalytic ability of the enzyme. Mutations were made in MOE by redrawing the residues and minimizing structures obtained. Docking studies were performed with all mutated enzymes and bis(adenosine)$5^{\prime}$-tetraphosphate in order to find out how mutations affect enzymatic action. The structure of adenylate kinase was obtained from RCSB (PDB Id: 2c9y).

\section{Results and Discussion}

3.1. Modeling and Docking of HArgS. Homology modeling of HArgS with a single template was performed by MOE, and a standard molecular mechanics forcefield-amber99 [46] was used. Ten models were generated, and the model was optimized by energy minimization. Phi-psi plot or 
TABLE 1: Fitness function values, interactions with the enzyme, total energies, and energies of binding with the $\alpha$-carboxyl group of the compounds investigated.

\begin{tabular}{lcl}
\hline Compound & Fitness function & Interactions with the enzyme \\
\hline Arg & 46.4 & $\begin{array}{l}\text { Two interactions between Glu130-Gu group and Asp326-Gu group } \\
\text { and 2 interactions between Arg325- } \alpha \text {-carboxyl group, } \\
\text { Glu269- } \alpha \text {-carboxyl group, Gly172- } \alpha \text {-amino group }\end{array}$ \\
\hline NCan & 32.98 & $\begin{array}{l}\text { Glu130-oxyamino group, Asp326- } \alpha \text {-amino group, and } \\
\text { His353- } \alpha \text {-carboxyl group }\end{array}$ \\
\hline NCav & 44.09 & $\begin{array}{l}\text { Two interactions between Glu130-oxyGu group, Tyr322, } \\
\text { Asn135- } \alpha \text {-carboxyl group, Tyr170, and Ser133- } \alpha \text {-amino group }\end{array}$ \\
\hline Cav & 36.8 & $\begin{array}{l}\text { Two interactions between Glu130-oxyGu group, Tyr322, Asp135, } \\
\text { Gly172- } \alpha \text {-carboxyl group, and Leul71- } \alpha \text {-amino group }\end{array}$ \\
\hline NsArg & 44.04 & $\begin{array}{l}\text { Glu130, Asp326-sulfoGu group, Asp326, Tyr344-sulfoGu group, } \\
\text { Tyr322-SO } \\
\text { Asn135- } \alpha \text {-carboup, Ser133- } \alpha \text {-amino group, Glu269, and }\end{array}$ \\
\hline sArg & 46.78 & $\begin{array}{l}\text { Two interactions between Glu130-sulfoGu group, Tyr322-SO }{ }_{2} \text { group, } \\
\text { Asp135, Glyl72- } \alpha \text {-carboxyl group, and Ser133- } \alpha \text {-amino group }\end{array}$ \\
\hline
\end{tabular}

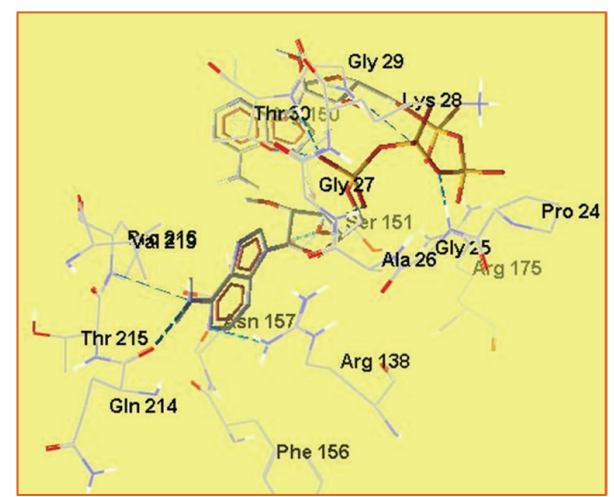

FIGURE 6: Interactions in the active site of ADK with bis(adenosine)$5^{\prime}$-tetraphosphate.

Ramachandran plot for the chosen model is presented on Figure 3.

Disallowed regions are less than $1 \%$, according to the Ramachandran plot, so it could be used in further studies. The selected model was also checked by docking.

It is known [47] that ATP binds to the loop close to the binding site of arginine. This helps the forming of the arginylAMP. It interacts electrostatically with Arg325 (Figure 4(a)). When there is no ATP molecule attached to HArgS, arginine binds as shown in Figure 4(b). All the H-bonding capability of the substrate is used by the protein for the specific recognition. The $\alpha$-amino group of arginine forms $\mathrm{H}$-bonds with main chain carbonyls of Ser133 and Phe134, while $\alpha$ carboxylate interacts with the amide nitrogen of Asn135 and phenyl oxygen of Tyr322. Residues Ser133 and Asn135 are very important for correct recognition of $\alpha$-amino and $\alpha$-carboxyl groups. The guanidinium group forms two salt bridges with two carboxylate residues: Glu130 and Asp326. If ATP binds, some conformational changes occur, and $\alpha$-carboxyl group of arginine interacts with Arg325, and this facilitates forming the arginyl-AMP (Figure 4(c)).
TABLE 2: Total energies of the complexes and fitness function values of $b i$ (adenosine) $-5^{\prime}$-tetraphosphate with ADK and mutated ADK.

\begin{tabular}{lcc}
\hline Mutation & $\begin{array}{c}\text { Total energy of } \\
\text { the complex }\end{array}$ & $\begin{array}{c}\text { Fitness function } \\
\text { value }\end{array}$ \\
\hline Without any mutation & -135.483 & 69.29 \\
Arg138 and Arg175 & -112.329 & 68.08 \\
Cav138, Arg175 & -147.651 & 90.30 \\
NCav138, Arg175 & -102.358 & 97.74 \\
sArg138, Arg175 & -128.855 & 68.08 \\
Arg138, Cav175 & -127.472 & 93.76 \\
Arg138, NCav175 & -131.506 & 96.24 \\
Arg138, sArg175 & & \\
\hline
\end{tabular}

Dockings with oxy- and sulfoanalogues of arginine were performed in order to check if they can act as substrates for this enzyme.

The interactions between the compounds and enzyme are listed in Table 1. Glu130 is an important site for substrate recognition in the enzyme. It binds to the guanidinium group of arginine. In the molecule of NCan, there is no guanidinium group and such interaction does not appear. Fitness function value for NCan is the lowest in this series of compounds. The distance between its $\alpha$-carboxyl group and Arg326 is too long to interact with it and thus to react successfully with ATP (Figure 5(a) and Table 2).

NsArg has a sulfoguanidinium group, and though it is less polar than arginine's guanidinium group, interaction with Glu130 is still present. In the case of this compound, we have additional interaction of the sulfogroup with Tyr322. The carboxyl group interacts with other residues from the active site, and the distance between this group and Arg325 is too long (Figure 5(b)).

In the case of sArg, the possibility for interaction between sArg and ATP is higher than NsArg as its $\alpha$-carboxyl group is closer to Arg325 (Figure 5(b)). 


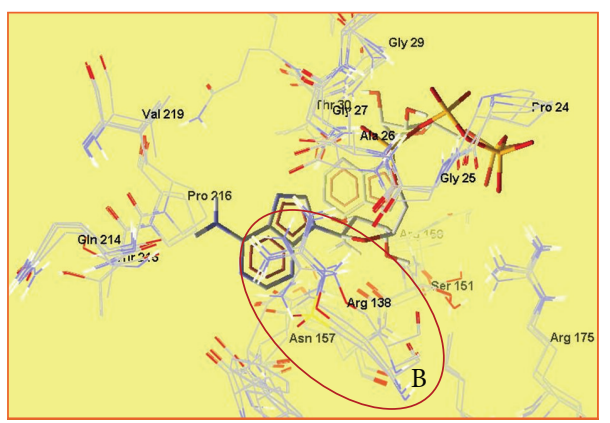

(a)

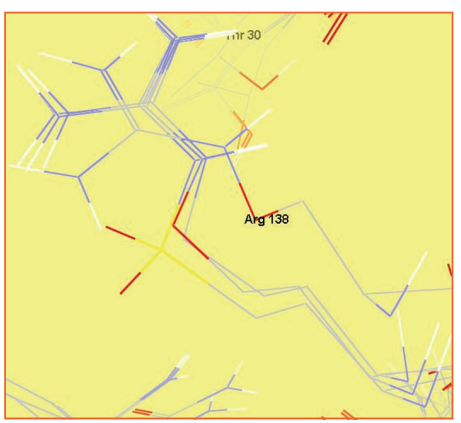

(b)

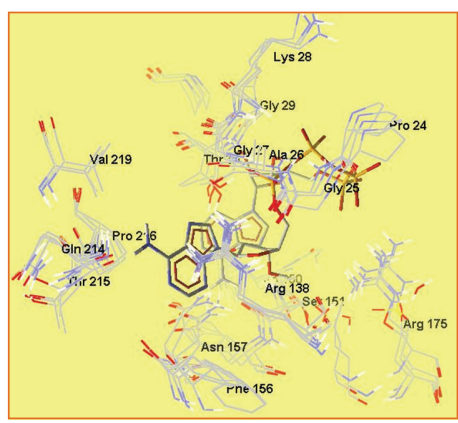

(c)

FIGURE 7: Superposed active sites of ADK and Arg138 mutated ADK with bis(adenosine)- $5^{\prime}$-tetraphosphate (a); focus on Arg138 residue in Arg138 mutated enzymes (b); superposed active sites of ADK and Arg175 mutated ADK with bis(adenosine)- $5^{\prime}$-tetraphosphate (c).

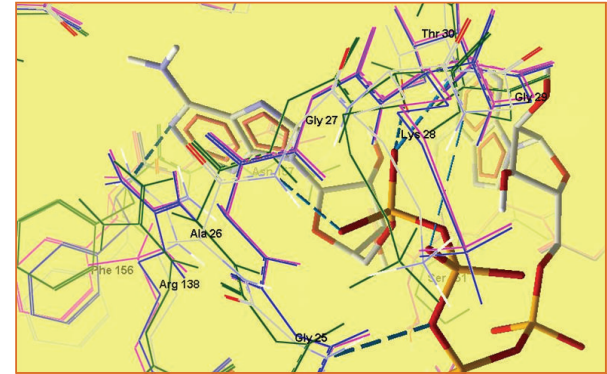

(a)

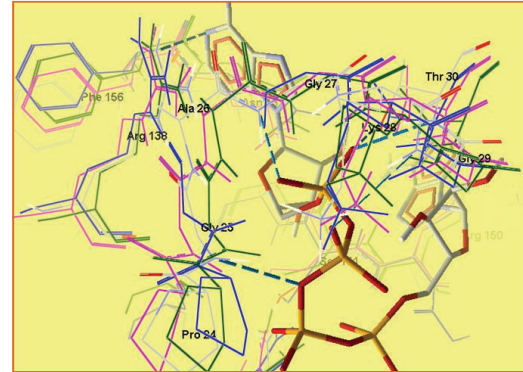

(b)

FIGURE 8: Superposition of the sequence GAGKG (25-29): (a) ADK and ADK mutated with Cav138 (blue), NCav138 (green), and sArg138 (purple); (b) ADK and ADK mutated with Cav175 (blue), NCav175 (green), and sArg175 (purple).

The enzyme can recognize NCav and Cav as substrates, but only Cav could interact with ATP to form Cav-AMP. The distance between $\alpha$-carboxyl group and Arg325 is too long to have a reaction with ATP (Figure 5(a)).

From this series of arginine analogues, we could mark three of them that could play the role of substrates for HArgS. These compounds could be incorporated in different peptides and protein molecules, and in the present work, we are analyzing the effects of this interaction on adenylate kinase.

3.2. Docking of Mutant Adenylate Kinases (ADK). With the help of MOE, we made mutations at two points subsequently in the active site of ADK-Arg138 and Arg175, with Cav, NCav, and sArg. After energy minimizations of 6 new structures, docking with bis(adenosine)-5' - tetraphosphate was performed with GOLD. Bis(adenosine)- $5^{\prime}$-tetraphosphate could mimic the interactions in the binding sites of ADK as it occupies both sites of the enzyme.

For the recognition of purine moiety of the substrate, very important residue is needed, Arg138, which interacts by a $\mathrm{p}-\pi$ interaction.

Second important point in enzyme sequence is GAGKG (residues 25-29). It is conserved and fully closed over substrate molecule. It interacts with all phosphate oxygen atoms of ADP molecule by forming hydrogen bonds with backbone amide groups (Figure 6).
All three analogues of arginine have the guanidinium group as a structural element. In all three cases, it is connected via more electronegative atoms (oxygen and sulfur) than the carbon atom; thus, it is less polar than guanidinium group of Arg. In all three mutations of Arg138 with its analogues, the typical site for ADP recognition still remains, and the purine moiety binds respectively, to oxy-, and sulfoguanidinium group. In the cases of Cav138 and sArg138 mutations, total energies of the enzyme-substrate complexes decrease, while in the case of Cav138 mutation, total energy increases. Fitness function value is almost the same when Arg138 is replaced by Cav, due to their structural similarity, and conformational changes in that case are very small (Figures 7(a) and 7(b)). When Arg138 is replaced by NCav and sArg, conformational changes in the binding site of the enzyme are bigger, and fitness function values are higher which is connected to the binding affinity of the substrate. The higher the fitness function value, the higher the affinity of the substrate to the enzyme and it will bind more strongly. This will decrease the rate of the enzymatic reaction and most probably will stop it in the case of NCan138 and sArg138.

Mutations in position Arg175 do not affect the enzyme much. There are some conformational changes and the values of fitness function indicate that, but newly formed enzymesubstrate complexes have total energies not very different from that of wild type enzyme-substrate complex. These 
mutations do not affect Arg138 and the binding site for purine moiety remains unchanged (Figure $7(\mathrm{c})$ ).

Exploring the sequence GAGKG in the case of Arg138 mutation, the biggest conformational changes occurred when Arg138 is replaced by NCav (Figure 8(a)).

In all mutations in position 175 , conformational changes are significant (Figure 8(b)). Purine moiety could be recognized by the mutant enzyme, but because of the changes in the site responsible for interaction between two ADP molecules, reaction could not be performed. These mutations could lead to inactive enzyme.

\section{Conclusion}

From previously synthesized and biologically tested arginine analogues, three of them Cav, NCav, and sArg could act as its antimetabolites. They could be recognized by arginylatetRNA synthetase as substrates and could be included in numerous biologically important peptides and proteins. Once they become an element of proteins' sequence, for example, enzymes, they would cause crucial changes in their structure leading to loss of enzymatic action. As long as these compounds exhibit a prolonged biological effect, this most probably is due to their incorporation into important metabolic enzymes.

\section{Acknowledgments}

This work was supported by NFSR of Bulgaria Project DVU 01/197 and COST Action CM0801 Project DO 02135/31.07.2009. Special thanks are due to Professor Edward W. Randall, Queen Mary, University of London, for the proofreading and editing of the paper.

\section{References}

[1] L. P. Mašič, "Arginine mimetic structures in biologically active antagonists and inhibitors," Current Medicinal Chemistry, vol. 13, no. 30, pp. 3627-3648, 2006.

[2] M. J. Harms, J. L. Schlessman, G. R. Sue, and E. Bertrand GarcíaMoreno, "Arginine residues at internal positions in a protein are always charged," Proceedings of the National Academy of Sciences of the United States of America, vol. 108, no. 47, pp. 18954-18959, 2011.

[3] G. J. Bartlett, C. T. Porter, N. Borkakoti, and J. M. Thornton, "Analysis of catalytic residues in enzyme active sites," Journal of Molecular Biology, vol. 324, no. 1, pp. 105-121, 2002.

[4] J. Kim, J. Mao, and M. R. Gunner, "Are acidic and basic groups in buried proteins predicted to be ionized?" Journal of Molecular Biology, vol. 348, no. 5, pp. 1283-1298, 2005.

[5] A. A. Bogan and K. S. Thorn, "Anatomy of hot spots in protein interfaces," Journal of Molecular Biology, vol. 280, no. 1, pp. 1-9, 1998.

[6] R. L. Cutler, A. M. Davies, S. Creighton et al., "Role of Arginine38 in regulation of the cytochrome $c$ oxidation-reduction equilibrium," Biochemistry, vol. 28, no. 8, pp. 3188-3197, 1989.

[7] P. J. Winn, S. K. Lüdemann, R. Gauges, V. Lounnas, and R. C. Wade, "Comparison of the dynamics of substrate access channels in three cytochrome p450s reveals different opening mechanisms and a novel functional role for a buried arginine," Proceedings of the National Academy of Sciences of the United States of America, vol. 99, no. 8, pp. 5361-5366, 2002.

[8] J. L. Hansen, A. M. Long, and S. C. Schultz, "Structure of the RNA-dependent RNA polymerase of poliovirus," Structure, vol. 5, no. 8, pp. 1109-1122, 1997.

[9] R. C. Wade, R. R. Gabdoulline, S. K. Lüdemann, and V. Lounnas, "Electrostatic steering and ionic tethering in enzymeligand binding: insights from simulations," Proceedings of the National Academy of Sciences of the United States of America, vol. 95, no. 11, pp. 5942-5949, 1998.

[10] Y. Jiang, V. Ruta, J. Chen, A. Lee, and R. MacKinnon, “The principle of gating charge movement in a voltage-dependent $\mathrm{K}^{+}$ channel," Nature, vol. 423, no. 6935, pp. 42-48, 2003.

[11] S. B. Long, E. B. Campbell, and R. MacKinnon, "Voltage sensor of Kv1.2: structural basis of electromechanical coupling," Science, vol. 309, no. 5736, pp. 903-908, 2005.

[12] X. Tao, A. Lee, W. Limapichat, D. A. Dougherty, and R. MacKinnon, "A gating charge transfer center in voltage sensors," Science, vol. 328, no. 5974, pp. 67-73, 2010.

[13] N. P. Le, H. Omote, Y. Wada, M. K. Al-Shawi, R. K. Nakamoto, and M. Futai, "Escherichia coli ATP synthase $\alpha$ subunit Arg376: the catalytic site arginine does not participate in the hydrolysis/synthesis reaction but is required for promotion to the steady state," Biochemistry, vol. 39, no. 10, pp. 2778-2783, 2000.

[14] R. Rammelsberg, G. Huhn, M. Lübben, and K. Gerwert, “Bacteriorhodopsin's intramolecular proton-release pathway consists of a hydrogen-bonded network," Biochemistry, vol. 37, no. 14, pp. 5001-5009, 1998.

[15] H. Luecke, H.-T. Richter, and J. K. Lanyi, "Proton transfer pathways in bacteriorhodopsin at 2.3 angstrom resolution," Science, vol. 280, no. 5371, pp. 1934-1937, 1998.

[16] S. Futaki, T. Suzuki, W. Ohashi et al., "Arginine-rich peptides. An abundant source of membrane-permeable peptides having potential as carriers for intracellular protein delivery," Journal of Biological Chemistry, vol. 276, no. 8, pp. 5836-5840, 2001.

[17] H. D. Herce and A. E. Garcia, "Molecular dynamics simulations suggest a mechanism for translocation of the HIV-1 TAT peptide across lipid membranes," Proceedings of the National Academy of Sciences of the United States of America, vol. 104, no. 52, pp. 20805-20810, 2007.

[18] P. B. Crowley and A. Golovin, "Cation- $\pi$ interactions in proteinprotein interfaces," Proteins, vol. 59, no. 2, pp. 231-239, 2005.

[19] D. F. Savage, J. D. O’Connell III, L. J. W. Miercke, J. Finer-Moore, and R. M. Stroud, "Structural context shapes the aquaporin selectivity filter," Proceedings of the National Academy of Sciences of the United States of America, vol. 107, no. 40, pp. 17164-17169, 2010.

[20] O. Boudker, R. M. Ryan, D. Yernool, K. Shimamoto, and E. Gouaux, "Coupling substrate and ion binding to extracellular gate of a sodium-dependent aspartate transporter," Nature, vol. 445, no. 7126, pp. 387-393, 2007.

[21] M. R. Stallcup, "Role of protein methylation in chromatin remodeling and transcriptional regulation," Oncogene, vol. 20, no. 24, pp. 3014-3020, 2001.

[22] C. Walsh, "Enabling the chemistry of life," Nature, vol. 409, no. 6817, pp. 226-231, 2001.

[23] P. P. Dzeja, K. T. Vitkevicius, M. M. Redfield, J. C. Burnett, and A. Terzic, "Adenylate kinase-catalyzed phosphotransfer in the myocardium: increased contribution in heart failure," Circulation Research, vol. 84, no. 10, pp. 1137-1143, 1999. 
[24] S. P. Bessman and C. L. Carpenter, "The creatine-creatine phosphate energy shuttle," Annual Review of Biochemistry, vol. 54, pp. 831-862, 1985.

[25] P. P. Dzeja, R. J. Zeleznikar, and N. D. Goldberg, "Adenylate kinase: kinetic behavior in intact cells indicates it is integral to multiple cellular processes," Molecular and Cellular Biochemistry, vol. 184, no. 1-2, pp. 169-182, 1998.

[26] P. Dzeja, A. Kalvenas, A. Toleikis, and A. Praskevicius, "The effect of adenylate kinase activity on the rate and efficiency of energy transport from mitochondria to hexokinase," Biochemistry International, vol. 10, no. 2, pp. 259-265, 1985.

[27] S. Kubo and L. H. Noda, "Adenylate kinase of porcine heart," European Journal of Biochemistry, vol. 48, no. 2, pp. 325-331, 1974.

[28] F. D. Laterveer, K. Nicolay, and F. N. Gellerich, "Experimental evidence for dynamic compartmentation of ADP at the mitochondrial periphery: coupling of mitochondrial adenylate kinase and mitochondrial hexokinase with oxidative phosphorylation under conditions mimicking the intracellular colloid osmotic pressure," Molecular and Cellular Biochemistry, vol. 174, no. 1-2, pp. 43-51, 1997.

[29] P. P. Dzeja and A. Terzic, "Phosphotransfer reactions in the regulation of ATP-sensitive $\mathrm{K}^{+}$channels," FASEB Journal, vol. 12, no. 7, pp. 523-529, 1998.

[30] J. R. Elvir-Mairena, A. Jovanovic, L. A. Gomez, A. E. Alekseev, and A. Terzic, "Reversal of the ATP-liganded state of ATPsensitive $\mathrm{K}^{+}$channels by adenylate kinase activity," Journal of Biological Chemistry, vol. 271, no. 50, pp. 31903-31908, 1996.

[31] J. A. Gutierrez and L. N. Csonka, "Isolation and characterization of adenylate kinase (adk) mutations in Salmonella typhimurium which block the ability of glycine betaine to function as an osmoprotectant," Journal of Bacteriology, vol. 177, no. 2, pp. 390400, 1995.

[32] L. Karl Olson, W. Schroeder, R. Paul Robertson, N. D. Goldberg, and T. F. Walseth, "Suppression of adenylate kinase catalyzed phosphotransfer precedes and is associated with glucoseinduced insulin secretion in intact HIT-T15 cells," Journal of Biological Chemistry, vol. 271, no. 28, pp. 16544-16552, 1996.

[33] W. Bandlow, G. Strobel, C. Zoglowek, U. Oechsner, and V. Magdolen, "Yeast adenylate kinase is active simultaneously in mitochondria and cytoplasm and is required for nonfermentative growth," European Journal of Biochemistry, vol. 178 , no. 2, pp. 451-457, 1988.

[34] http://www.uniprot.org.

[35] B. Delagoutte, D. Moras, and J. Cavarelli, "tRNA aminoacylation by arginyl-tRNA synthetase: induced conformations during substrates binding," EMBO Journal, vol. 19, no. 21, pp. 55995610, 2000.

[36] T. Dzimbova, I. Iliev, K. Georgiev, R. Detcheva, A. Balacheva, and T. Pajpanova, "In vitro assessment of the cytotoxic effects of hydrazide derivatives of unnatural amino acids," in Peptides: Building Bridges Proceedings of the 22nd American Peptide Symposium, M. Lebl, Ed., pp. 392-393, 2011.

[37] T. Dzimbova, I. Iliev, R. Detcheva, A. Balacheva, and T. Pajpanova, "In vitro assessment of the cytotoxic effects of hydrazide derivatives of sulfoarginines in 3T3 and HepG2 cells," in Proceedings of the Collection Symposium Series, vol. 13, pp. 3436, 2011.

[38] T. Dzimbova, E. Miladinova, S. Mohr et al., "Sulfo- and oxy-analogues of arginine: synthesis, analysis and preliminary biological screening," Croatica Chemica Acta, vol. 84, no. 3, pp. 447-453, 2011.
[39] T. Dzimbova, I. Iliev, K. Georgiev, R. Detcheva, A. Balacheva, and T. Pajpanova, "In vitro assessment of the cytotoxic effects of sulfo-arginine analogues and their hydrazide derivatives in 3T3 and HepG2 cells," Biotechnology \& Biotechnological Equipment, vol. 26, pp. 180-184, 2012.

[40] Molecular Operating Environment (MOE), 2012, 10, Chemical Computing Group Inc., 1010 Sherbooke St. West, Suite \#910, Montreal, QC, Canada, H3A 2R7, 2012.

[41] G. Jones, P. Willett, R. C. Glen, A. R. Leach, and R. Taylor, "Development and validation of a genetic algorithm for flexible docking," Journal of Molecular Biology, vol. 267, no. 3, pp. 727748, 1997.

[42] http://www.scientificlinux.org.

[43] http://molegro.com/index.php.

[44] R. Thomsen and M. H. Christensen, "MolDock: a new technique for high-accuracy molecular docking," Journal of Medicinal Chemistry, vol. 49, no. 11, pp. 3315-3321, 2006.

[45] http://www.rcsb.org.

[46] W. D. Cornell, P. Cieplak, C. I. Bayly et al., "A second generation force field for the simulation of proteins, nucleic acids, and organic molecules," Journal of the American Chemical Society, vol. 117, no. 19, pp. 5179-5197, 1995.

[47] J. Cavarelli, B. Delagoutte, G. Eriani, J. Gangloff, and D. Moras, "L-arginine recognition by yeast arginyl-tRNA synthetase," EMBO Journal, vol. 17, no. 18, pp. 5438-5448, 1998. 

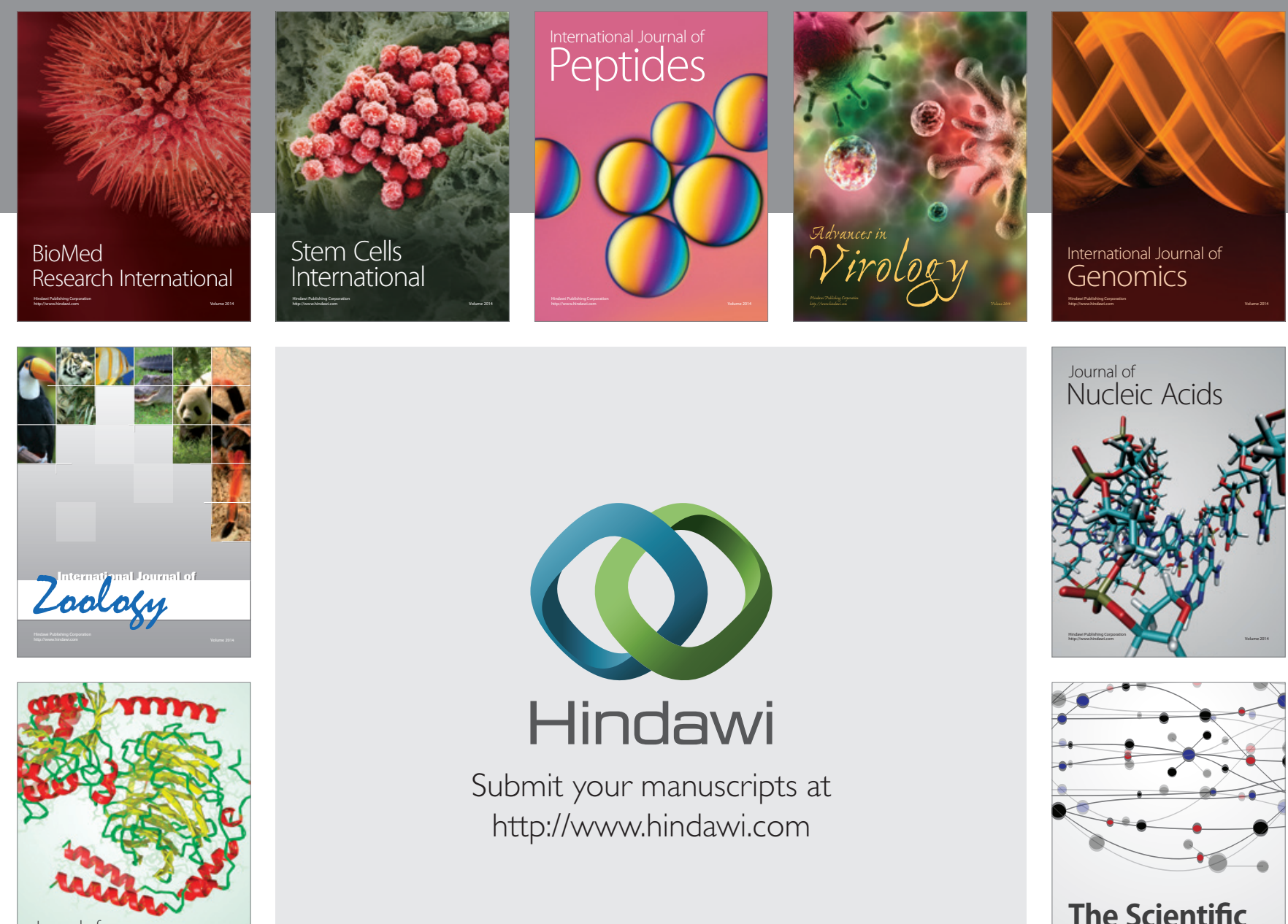

Submit your manuscripts at

http://www.hindawi.com

Journal of
Signal Transduction
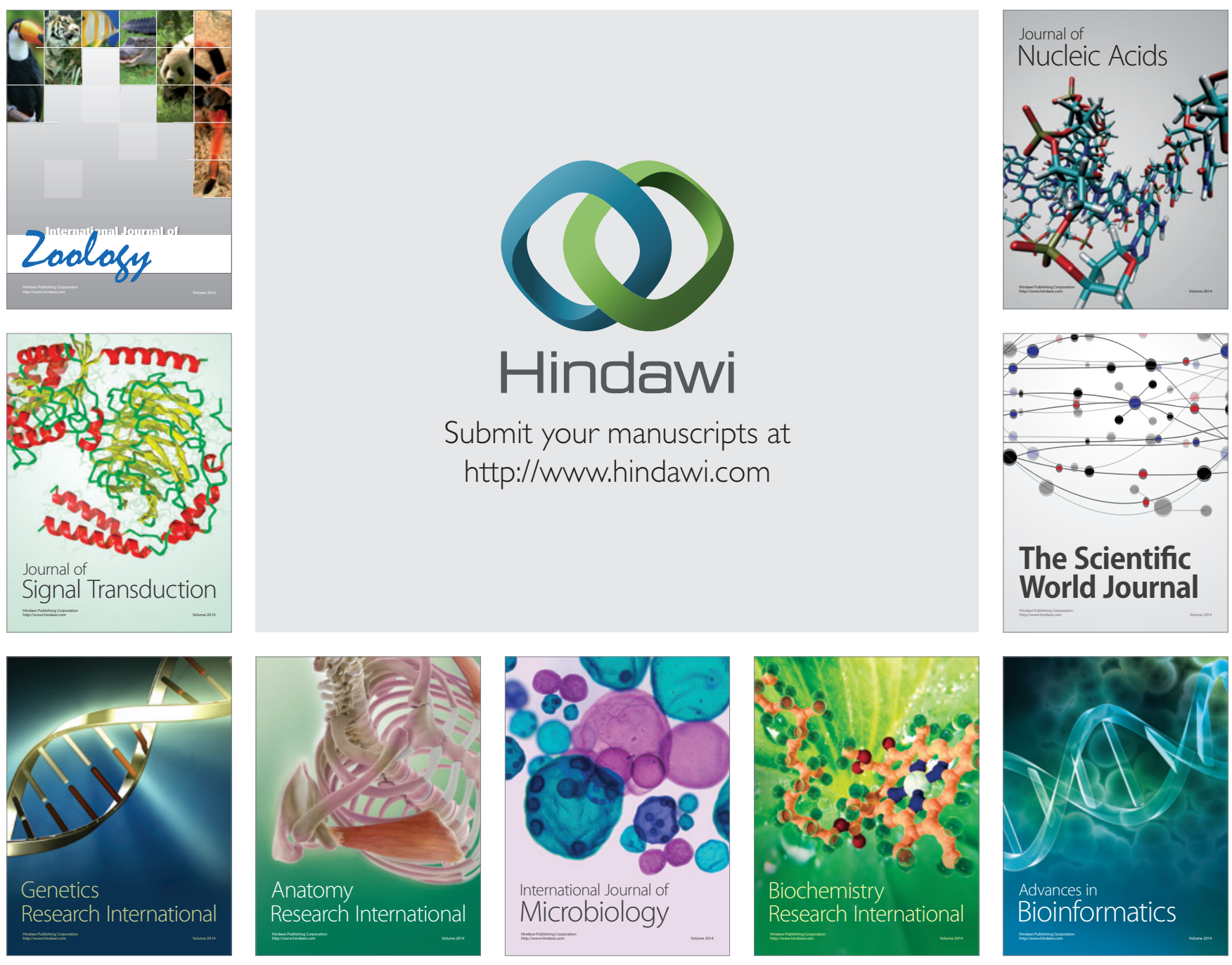

The Scientific World Journal
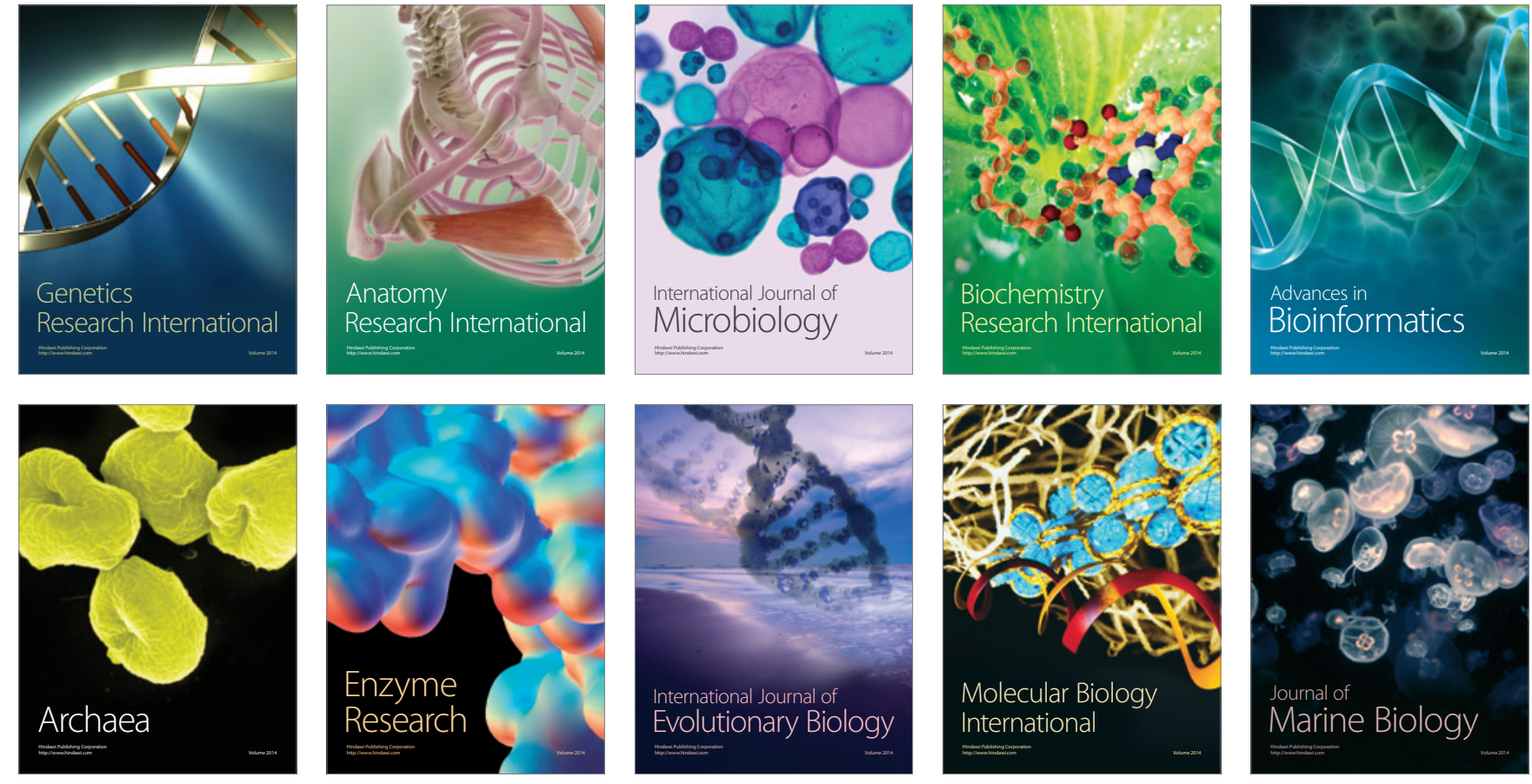